\title{
Community of Practice: An Effective Way to ESL Teacher Professional Development in Vocational Colleges
}

\author{
Shan Kong ${ }^{1}$ \\ ${ }^{1}$ School of Foreign Studies, Yiwu Industrial \& Commercial College, Yiwu, Zhejiang, China \\ Correspondence: Shan Kong, School of Foreign Studies, Yiwu Industrial \& Commercial College, Yiwu, \\ Zhejiang Province, China. Tel: 86-15868930978. E-mail: 417265541@qq.com
}

Received: May 15, 2018 Accepted: June 22, 2018 Online Published: June 24, 2018

doi: 10.5539/elt.v11n7p158 URL: http://doi.org/10.5539/elt.v11n7p158

\begin{abstract}
Teacher professional development is essential to English teaching reform in vocational colleges. Community of practice presents a new way for professional development of ESL teachers in vocational colleges in China. This paper introduces and discusses the process of creating and exploring ESL teacher community of practice in a vocational college. And it points out that teacher community of practice is an effective way to teacher professional development.
\end{abstract}

Keywords: community of practice, professional development, ESL teachers, vocational colleges

The current education reform in China requires teachers to become educational practitioners, researchers and innovators, and to face new challenges and tasks with a positive attitude. A large number of ESL teaching practices have proved that there is a very close relationship between the professional development of ESL teachers and the reform of ESL teaching. The professional development of ESL teachers is an effective way to improve the overall professional quality and teaching level of ESL teachers and promote the reform of ESL teaching. However, the research shows that the current professional development of ESL teachers in vocational colleges is not optimistic.

The ESL teachers in vocational colleges in China are generally younger, lacking of teaching experiences, so they cannot teach students and integrate teaching resources in accordance with students' levels as well as social requirements. In addition, the lack of high-level teachers and scientific research capabilities and methods make ESL teachers' awareness and level of scientific research relatively weak in vocational colleges. Compared with teachers of other disciplines, the number and quality of academic papers and books published by ESL teachers in vocational colleges are at a disadvantage.

Furthermore, there is a certain contradiction between the work intensity of ESL teachers and the need for professional development in vocational colleges. The heavy emphasis on teaching workload makes most ESL teachers in vocational colleges pay no attention to their professional development. Although ESL teachers in vocational colleges have some opportunities for on-the-job training or further study visits, which can play a role in the short term, it is still difficult to completely solve the problems teachers face in their teaching practice due to the lack of sustainable influence and support. It can hardly meet the needs of professional development of teachers.

Apart from the above problems, quite a number of ESL teachers in vocational colleges regard teaching as an individual job, who are unwilling to collaborate with other teachers. This isolated and unopened situation has greatly hindered their professional development and made them "congenitally deficient, acquired fatigue."

Nowadays, the ongoing reform of English teaching in vocational colleges in China is developing in depth toward the direction of "Strengthening Teacher Development and Curriculum Construction" after the initial success of the "Improving Teaching Models". Therefore, finding a professional development path that is practical, low cost, high efficiency, and wide applicability is a must for ESL teachers in vocational colleges.

\section{Enlightenment of "Community of Practice" to Professional Development of ESL Teachers in Vocational Colleges}

The proposal of the "Community of Practice" theory has opened up a new way for us to solve this problem. The concept of "Community of Practice" was first proposed by Lave and Wenger (2004) to illustrate the importance 
of social activities linking individuals to communities and the significance of the community in legalizing individual practices. It upholds the ideological essence of "community vision", "sharing mechanism", "conversation atmosphere", and "cooperative culture" in the "community" theory. At the same time, it pays more attention to participants" status of "legitimate marginal participation".

A community of practice is a group of learners who work together to communicate with each other, share learning resources, and accomplish tasks together so that they can continuously improve themselves and gradually influence and help each other. Mutual promotion of good interpersonal relationships ultimately leads to individual growth and common development.

Furthermore, the achievements created by the community of practice are of collective wisdom, which are rich in practical features. They are the insights and consensus reached after the interactions and dialogues among community members. Every member of the community can understand the theoretical and practical value of the achievements, take its essence, and transform and recreate it. Ultimately, he creates his own unique style on the basis of practice. Adhering to the principles of sharing, openness, and trust, members of the community boldly explore and try out new knowledge and continue to summarize, examine, and reflect on it, so as to build a brand new community culture of practice.

The concept of community of practice fits well with the professional characteristics and the identities of teachers in the process of their professional development. It focuses on solving practical problems in teaching and has important implications in changing the situation of "disassociation between knowledge and practice" in teacher education and promoting teachers' professional development.

Therefore, in October 2017, the ESL teachers of our college launched a research project on the "Professional Development of ESL Teachers Based on the "Community of Practice", hoping to make good use of the "teacher group", an accessible but precious resource for professional development. By means of various forms of practical community activities, the sharing, transmission, and exchange of knowledge and experiences are realized, so that the professionalism of each member is continuously enriched and improved, and eventually common development is achieved.

\section{Creating and Exploring "ESL Teacher Community of Practice" in a Vocational College}

At the beginning of the project, the teacher community of practice was established by the voluntary registration of the ESL teachers of our college. A total of 16 teachers joined the group. With regards to the activities of the teacher community of practice, the spontaneity and autonomy of the teachers' professional learning are of utmost importance. So it is necessary to discover the common vision of the community members. The common vision is the value orientation and direction of efforts of each member, and is the core culture that launches community activities.

Thus, we conducted a questionnaire survey among all members at the beginning of the study. The investigation involved the basic background of the teachers, their current teaching research situation, and attitudes as well as expectations for the teacher community of practice. The survey results clearly showed that all members had extremely strong demands for improving their teaching and scientific research capabilities. Everyone was eager to share and exchange the achievements and difficulties in teaching and research with their colleagues. They all believed that the activities of the teacher community of practice could promote their professional development.

For effectively improving the ESL teachers' teaching and scientific research capabilities, after the investigation and discussion, we divided them into small groups. The teacher groups gathered regularly, and made meeting records. At the same time, we organized various forms of practical community activities and asked the teachers to write research journals to record their feelings and reflections in teaching and research. After a year of exploration and practice, we believe that the teacher community of practice has promoted the professional development of the ESL teachers in the following aspects.

\subsection{Constructing a Cooperative Culture for Teacher Professional Development}

As a learning theory, the "Community of Practice" theory is essentially a constructive social context learning model. The essence of the theory is to promote barrier-free dialogue and exchange among members of the community, and to create an equal dialogue-style cultural atmosphere. Above all, the members of the community must change their conservative attitudes, strengthen their sense of cooperation, and engage in dialogues, exchanges, cooperation, resources sharing, and complementary advantages with other teachers with an open and trusting attitude. This will promote their professional development and common growth.

For this reason, we did not set a threshold for community activities and gave everyone full freedom. All activities were decided by each member and measures were taken to encourage the teachers to dare to speak and express 
their opinions. The organization mechanism of equality and democracy provided the community members with relaxed and beneficial conditions for their professional development. In this situation, everyone felt comfortable and safe and would speak out doubts or failures in their career and share their successful experiences with others. In the culture of cooperation, telling the stories of failure was not just to admit mistakes, but to inspire other members to learn from them. Similarly, talking about success was not to show off the achievements, but to reflect on successful experiences with everyone. The cooperative culture promoted mutual trust and respect among the members and made full use of everyone's potential.

For instance, in a group discussion event, our theme was to help students determine the interview questions for foreign business people at the Yiwu Fair. We used the "brainstorming" to allow all participating teachers to present their ideas and make their own suggestions. The teachers discussed very actively and enthusiastically at the meeting. Some thought that students should ask questions about the current hot issues in the interview, because they also needed to know about the current world affairs while they were practicing oral English. Others believed that the interview questions should be closely related to the local realities. It was natural and willing for foreigners to answer the questions about food, hotels and transportation etc. at the Yiwu Fair. Some teachers supposed that students should ask some interesting interview questions including "What is your favorite movie?", "What is your favorite song?", "Could you speak Chinese?" and so on. The collision of these thought sparks had greatly broadened everyone's horizon and created a community culture of cooperation.

\subsection{Establishing a Problem-solving Oriented Community Mechanism}

The improvement of teachers' professional level is largely an improvement in the level of teaching practice. Therefore, we are very concerned about the practical difficulties faced by the ESL teachers in the classroom. We established problem-solving oriented community mechanism, and the activities of teacher community of practice were centered on solving practical problems in the classrooms. Community members held regular meetings every two weeks to exchange and analyze problems and doubts in teaching, and discussed how to solve them. Besides, we also shared the successful experiences in teaching and jointly explored the ESL teaching models, teaching philosophy and methods that are consistent with our college. Each community member gained certain experiences and inspirations in the mutual discussion and which could be applied to his own classroom teaching practice.

For example, once a teacher mentioned at a meeting that the five-minute English presentation before the lesson did not achieve the expectations. Though the English presentation was only a few minutes, she believed that the students on the stage could practice their speaking English and have courage to speak out. And the rest of the students could develop their listening comprehension skills. However, the actual situation was often like this: the student who did the presentation kept talking alone, and the other students did not listen carefully and kept busy doing their own things. There was no positive interaction between the speaker and the audience. In this regard, the ESL teachers presented their own "high tactics."A teacher suggested that the students who did presentation should be fully-prepared to supervise the other students to listen carefully by way of asking questions. Another teacher thought that the form of English presentation could be diversified. For example, a PPT could be produced and delivered in groups on topics that are of interest to the students. The illustrations could be helpful in stimulating the students' interest. A young teacher supposed that it was also a good choice for the students to come up with performances of English drama. According to her stories, to fully trust the students' abilities could always bring big surprises in her class. At the meeting, everyone had a lively discussion on this issue. The sharing and exchange of experiences with each other not only helps solve problems, but also bring lots of new perspectives.

\subsection{Conducting Effective Teacher Community Activities}

To ensure the effective implementation of the ESL teacher community activities, and make up the limitations of their learning time and resources, as well as effectively improve their teaching and scientific research capabilities, we had conducted a series of practical explorations as follows.

Firstly, we organized the ESL teachers to select some empirical teaching and research papers in the core journals of foreign languages to read. The academic papers were mainly selected from such journals as "Foreign Language Teaching and Research", "Foreign Language Circles", "Foreign Languages Academic Journal", "Foreign Languages and Foreign Language Teaching", and "Language Teaching and Research".

After careful reading, we asked the teachers to analyze and discuss the papers they chose in groups and fulfill the task. That was, the two teachers in each group collaborated to report and evaluate the literature in the form of PPT at the meeting. Apart from the reporting teachers, other teachers were also required to read these articles and were prepared to ask questions or answer questions at the meetings, which means all members were involved in 
the learning and discussion on the papers. Each group reported in turn. At the report, the teachers needed to answer several questions including "Why does the author want to conduct this research?", "What are the research questions?", "What research methods are used?", "How does the researcher implement the research?", "What are the results of the study?", and "What are the strengths and weaknesses of this study?" etc.

Six months later, we conducted an interview with the participating teachers on this teacher community activity. The results showed that most of the teachers thought that their interest in scientific research had increased and they no longer regarded it as a daunting task. Their abilities for selecting research projects and the use of research methods had been greatly improved. They could apply the knowledge they had gained from the teacher community activities to their teaching practice. And they could also conduct teaching from the perspective of reflection and research. Meanwhile, the teachers also made some valuable suggestions in the interview. For instance, some teachers believed that reading academic papers and discussion would be better linking to real classroom instruction. Some thought that the quality of articles in domestic journals is uneven, thus some good articles in foreign journals could also be considered. Furthermore, some teachers suggested that the teacher community could hold seminars on "Design \& Arguments on Scientific Research Projects".

Secondly, we used the way of lesson interpretation and assessment to help the ESL teachers find problems in their classroom teaching, and figured out solutions to the problems through discussion and analysis. Lesson interpretation is a useful method for teachers to self-reflect and self-examine their teaching, and it is also a process to help teachers improve their teaching ability. Lesson interpretation is the foundation and guarantee of classroom instruction, which can reflect a teacher's teaching and research abilities. Because the emphasis of the lesson interpretation is explanation and interpretation, which belongs to the category of teaching and research.

Teachers can help their peers clearly understand their own teaching ideas and instructional design by means of lesson interpretation. Then through discussion and analysis, teachers' individual ideas will integrate with collective wisdom, which can surely improve their traditional individual teaching model. The process of lesson interpretation and assessment can enable teachers to profoundly reflect on their own teaching and learn from others, thus improve their teaching design and methods, and eventually strengthen their teaching effectiveness.

Thirdly, we invited some experts to help enhance the professional standards of the ESL teacher community of practice. Their participation and instruction in our activities were significant. Professor Hongzhang Liu from Shanghai Jiaotong University, Professor Huilan Ying from Zhejiang University, Professor Xikang Ding from China Jiliang University, and Professor Xiaofang Luo and Professor Enpei Zhang from our college have been invited to participate in our activities and have given some relevant lectures for us such as Linguistic Studies, Teachers' Growth, Scientific Research Ability Training, and How to Present a Better Lesson Interpretation etc..

The autonomy of the community activities made the experts no longer the masters of the entire learning process. They were involved in activities as a "participant" or "leader". They provided professional support and help for teachers' learning, and inspired teachers' enthusiasm for learning and thinking. They did not directly instruct the teachers how to solve their problems. Instead, they encouraged the teachers to constantly reflect on their teaching and cooperate with others, so as to create their own practical knowledge.

Fourthly, in view of the heavy workload of the ESL teachers in vocational college, we did not have much time to get together and have discussions. To ensure the community activities going smoothly, the interaction and communication on the Internet have become a must.

We established a WeChat group, which was very convenient and user-friendly. The teachers could communicate and discuss in the group at any time to solve problems and doubts in their teaching and research. They could upload their curriculum design, lesson plans, lesson PPTs and teaching logs, etc. to the group share, and every group member could download and share the resources. This was a useful way to keep continuous communication and interaction among group members. The participating teachers shared common interests, who concerned about same issues, and could help each other and learn from each other. Eventually, all members would make progress together.

\section{Conclusion}

Through the activities of the teacher community of practice, the teaching and scientific research capabilities of the ESL teachers in our college have been greatly improved.

In the past year, the members of the teacher community of practice have successfully applied for two provincial and three municipal as well as three school-level teaching and research projects. Five teachers have published academic papers on the core journals in China. One teacher won the Second Prize in the Provincial Teaching Competition. And another teacher won the Advanced Individual for Scientific Research in our college. Four 
teachers have created an online open course "Shangcheng Oral English" and all the other community members are using the course.

The teacher community of practice has not only enhanced the ESL teachers' teaching and research abilities, but also strengthened the exchange and interaction among the members. In addition, it has also created a culture of teacher group that is "Positive, Sharing, Encouraging, and Harmonious".

Through the collaboration of teaching and research, ideological exchanges, experience sharing, and the common efforts, the ESL teachers in vocational colleges constantly refine their wisdom in teaching practice, so that they can integrate their teaching, learning, and research, and it will accompany the teachers' lifetime professional development.

\section{References}

Ali, B. (2016). Factors Affecting English as a Foreign Language Teachers' Participation in Online Communities of Practice: The Case of Webheads in Action. International Journal of Languages' Education and Teaching, 4, 20-35.

Anderson, C. A., LaShorage, S., \& Sharon, W. (2016). An Analysis of How Building a Collaborative Community of Professional Social Studies Teachers through Targeted Ambient Professional Development Impacts Social Studies Classroom Practices, Journal of Education and Training Studies, 4, 58-72.

Agnes, C. (2013). Using Multimedia Technology to Build a Community of Practice: Pre-Service Teachers' and Digital Storytelling in South Africa. International Journal of Education and Development using Information and Communication Technology, 9, 17-27.

Dufour, R. (2004). Schools as learning communities. Educational Leadership, 8, 6-11.

Hargreaves, A. (1992). Understanding Teacher Development. New York: Teachers College Press.

Hord, S. M. (1997). Professional Learning Communities: Communities of Continuous Inquiry and Improvement. Austin, TX: Southwest Educational Development Laboratory.

Lave, J., \& Wenger, E. (2004). Situated Learning: Legitimate Peripheral Participation. Shanghai: East China Normal University Press.

Wang, L. Y. (2010). Teachers' Practice Community: A Platform for Professional Development. Journal of Hebei Normal University, 8, 26-29.

Wenger, E. (1998). Community of practice: Learning, meaning, and identity. London: Cambridge University Press. https://doi.org/10.1017/CBO9780511803932

Wu, Z. J. (2008). Research Paradigm of Foreign Language Teacher Development. Foreign Language Learning Theory and Practice, 3, 55-60.

Zhang, P. (2009). Construction Strategies and Basic Experiences of School-based Teacher Practice Community. Global Education, 1, 88-90.

Zhang, P., \& Zhu, P. (2009). Teacher Practice Community: A New Perspective of Teacher Professional Development. Teacher Education Research, 2, 56-60.

Zhao, J. (2006). Learning Community-A Socio-cultural Analysis of Learning. Shanghai: East China Normal University Press.

Zhou, Y. (2005). Investigation and Research on the Development Needs of College English Teachers. Foreign Language Teaching and Research, 3, 206-210.

\section{Copyrights}

Copyright for this article is retained by the author(s), with first publication rights granted to the journal.

This is an open-access article distributed under the terms and conditions of the Creative Commons Attribution license (http://creativecommons.org/licenses/by/4.0/). 